\title{
Effect of Alumina and Halloysite clay on Electrical tree growth in Silicone Rubber Nanocomposite
}

\author{
M. Hafiz, C.M.Salmi ${ }^{1}$,M.Kamarol ${ }^{2}$, M.Mariatti $^{3}$ \\ ${ }^{1}$ Seberang Perai Polytechnic, 13500, Seberang Perai, Penang, Malaysia. \\ ${ }^{2}$ School of Electrical and Electronic Engineering, Universiti Sains Malaysia, Penang, Malaysia \\ ${ }^{3}$ School of Materials and Mineral Resources Engineering, Universiti Sains Malaysia, Penang, Malaysia
}

\begin{abstract}
Nowadays Silicone Rubber ( $\mathrm{SiR}$ ) is recommended in high voltage cable accessories fabrication as it offers excellent electrical and mechanical properties. Electrical tree is one of the phenomenon which contributes to the main factor of SiR insulation breakdown. Recently, a new approach has been applied in order to enhance the insulation strength properties by introducing nano filler in undoped material. Thus, this paper presents the influence of nano-alumina and halloysite nanoclay on electrical tree growth in SiR at 0,1 vol\%, 2 vol\% and 3 vol\% concentration. The electrical tree growth was investigated at $8 \mathrm{kVrms}$ after tree inception voltage (TIV) within 30 minutes under room temperature. The results show reductions of electrical tree growth speed and accumulate damage (\%) up to 2 vol\% nano-alumina and up to 3 vol\% halloysite nanoclay. Nevertheless the presence of $3 \mathrm{vol} \%$ nano-alumina in SiR leads to the faster electrical tree growth rate and the worst accumulate damage within 1 minute of electrical tree growth process.
\end{abstract}

Key words: Tree growth rate; accumulate damage; nano-alumina; halloyste nanoclay nanocomposites

\section{INTRODUCTION}

Recently Silicone Rubber (SiR) is widely implemented in XLPE cable accessories fabrication up to $500 \mathrm{kV}$ as it offers excellent electrical and mechanical properties. However, under the influence of high voltage stress it may contribute to the deterioration of the insulating material and finally lead to the degradation and cable failure. Normally underground cables are exposed to the moisture and contamination which can contribute to the generation of water tree, electrical tree and finally to the cable damage. Electrical tree is one of the main causes to the cable failure in underground cable where the electrical tree initiates at the fragile point of the cable, which may cause from the sharp edge, contaminations and voids [1-4].

Nowadays a few approaches have been taken by numerous researchers in order to enhance the electrical tree resistance in cable accessories fabrication such as improving the material preparation, upgrading the material selection and producing the dielectric material with inhibitor [5],[6]. For fast evolution of nano technology, nano filler has been found as one of the approaches in order to enhance and improve the electrical and mechanical properties in polymeric insulation fabrication. The presence of $\mathrm{SiO}_{2}$, $\mathrm{TiO}_{2}$, MMT and OMMT in Silicone Rubber (SiR), Low-density polyethylene (LDPE) and polyethylene (PE) have been reported and investigated [7-10]. Alapati et al have investigated that the presence of nano-alumina up to $5 \mathrm{wt} \%$ in LDPE nanocomposites has an ability to improve the electrical properties of the dielectric polymer such as partial discharge resistance, electrical tree length and tree inception voltage (TIV) [9]. Y. X. Zhou et al mentioned that more Bush type tree pattern could be observed regularly with the presence of $\mathrm{SiO}_{2}$ in $\mathrm{SiR}$. It shows that $\mathrm{SiO}_{2}$ can prolong the electrical tree growth rate in polymer nanocomposites compared to unfilled polymer [11]. Fairus et al mentioned that there is an improvement of electrical breakdown strength in SiR/EPDM nanocomposites with the inclusion of 2 vol\% nanoalumina [12]. A.Mohanty et al reported that Epoxy/Alumina nanocomposites shows better electrical insulation properties than unfilled Epoxy at a few wt\%

Corresponding Author: M. Hafiz, affilation, Seberang Perai Polytechnic, 13500, Seberang Perai, Penang, Malaysia., mhafiz@psp.edu.my 
of nano-alumina [13]. Morever, X. Huang et al have reported that nano-alumina has relatively high thermal conductivity, affordable price and offers for high electrical resistance resistivity [14].

On the other hand, N. Farzadnia et al have reported that $3 \mathrm{wt} \%$ of halloysite nanoclay has better compressive strength in cement mortar up to $24 \%$ than unfilled composite[15]. Besides, as reported by H. C. Voon et al and S. Rooj et al there is an improvement of mechanical properties in halloysite/Bovine Gelatin Films nanocomposites and halloysite/fluoroelastomer nanocomposites respectively with the presence of halloysite nanoclay[16],[17]. Although numerous researchers have reported that nano-alumina and halloysite nanoclay have the ability to improve the dielectric properties in few nanocomposites respectively, the influence of nano-alumina and halloysite nanoclay in $\mathrm{SiR}$ nanocomposites to the electrical tree growth mechanism has not yet been studied and reported.

Thus, this paper reports the influence of nanoalumina and halloysite nanoclay to the electrical tree growth at 0 to 3 vol\% concentration of fillers. The effect for both fillers at different concentration to the electrical tree growth in $\mathrm{SiR}$ nanocomposites are observed and analyzed. The electrical tree behaviour on electrical tree growth process such as electrical tree growth rate, and accumulate damage are discussed and presented.

\section{EXPERIMENT SET UP}

\section{Test Specimens Preparation}

Fig 1 shows configuration of test specimen sample where the needle electrode was put $2 \mathrm{~mm}$ from the grounded electrode. A $0.25 \mathrm{~mm}$ diameter of needle electrode was formed at $30^{\circ}$ tip angle and $5 \mu \mathrm{m}$ tip radius. A camera-equipped microscope was used to justify and confirm the interval gap of needle electrode to the ground electrode. SiR of (PT910-3) with the curing agent, (produced by Penchem) was employed as the base polymer. Alumina nano filler (13nm primary size, TEM $99.5 \%$ trace metals) and halloysite nanocaly $(50 \mathrm{~nm}$ average tube diameter, $15 \mathrm{~nm}$ inner lumen diameter and $1-3 \mu \mathrm{m}$ length) supplied by Sigma Aldrich, were selected to mix with the $\mathrm{SiR}$ base polymer separately. Both nanofillers were mixed with the $\mathrm{SiR}$ at $1 \mathrm{vol} \%, 2 \mathrm{vol} \%$ and $3 \mathrm{vol} \%$ individually. The unfilled $\mathrm{SiR}$ was also prepared for comparison. The weight ratio of $\mathrm{SiR}$ base polymer to its hardener was resolved at 10:1.

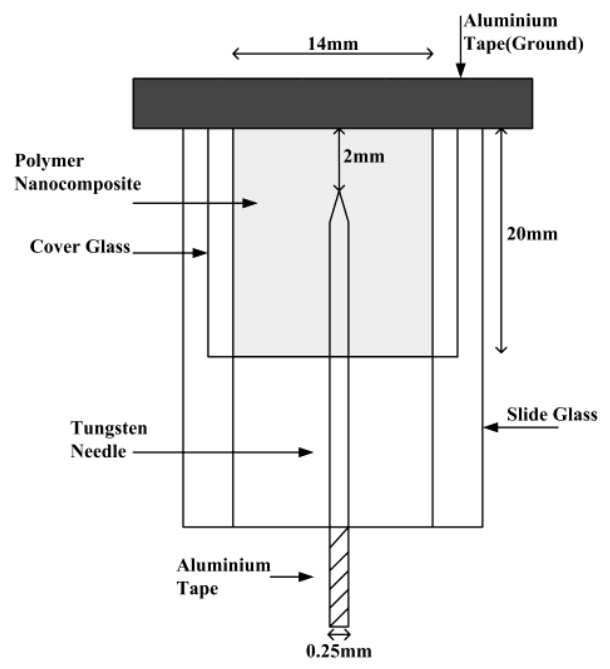

Fig 1 Configuration of block test specimen

The SiR was mixed with the nanofillers separately by using Ultrasonic mixer UP2005 for 10 minutes. Then, the sample was vacuumed for 60 minutes to remove generated voids by using 5831 National vacuum set. Another 10 minutes was required to remix the mixture with the hardener in order to cure the nanocomposites. The mixing process was performed by using Ultrasonic mixer UP2005. The mixture must be vacuumed again for 30 minutes by using 5831 National vacuum set to ensure all the generated voids were totally eliminated. Eventually, the SiR nanocomposites was poured on the slide glass mould. The dimension of the slide glass is $20 \mathrm{~mm} \mathrm{x}$ $14 \mathrm{~mm} \times 1 \mathrm{~mm}$ as shown in Fig 1 . The SiR nanocomposite was then covered by a slide cover glass and the sample was kept in room temperature for 24 hours for curing process.

\section{Experimental Apparatus}

Fig 2 illustrates the experimental set up to investigate the electrical tree growth process in $\mathrm{SiR}$ nanocomposites. A $5 \mathrm{kVA}, 240 \mathrm{~V} / 100 \mathrm{kV}, 50 \mathrm{~Hz}$ high voltage transformer was used as a power source for this studies. For each specimen tested, the supply voltage was increased by the rate of $0.5 \mathrm{kV} / \mathrm{sec}$ until the TIV was observed. Once the TIV was justified, the supply was kept constant at $8 \mathrm{kVrms}$ in order to monitor the electrical tree growth process. For this purpose, online monitoring system consists of a stereo microscope (Leica M165C), a digital camera (Leica MC170HD) and LCD personal computer monitor was configured. During the recording process, the magnification capability of monitoring system was set at 60 times magnification for the best quality image. 


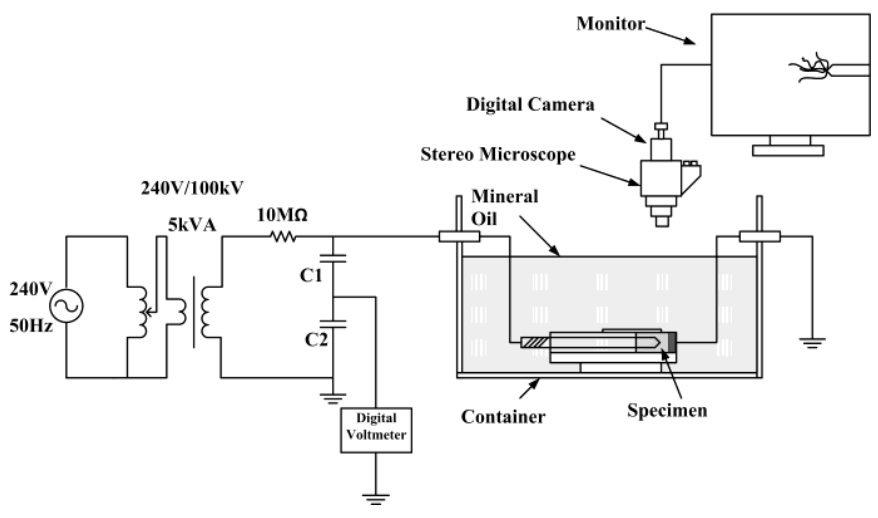

Fig 2 Set up arrangement for electrical tree observation

For the safety and precaution purpose, each of the samples tested was immersed into mineral oil in order to avoid surface flash over and the sample was placed directly below the lens of the camera. The process of electrical tree growth was monitored through the LCD personal computer monitor.

\section{RESULT AND DISCUSSION}

\section{Electrical Tree Growth Rate}

Fig 3 illustrates electrical tree growth rate as a function of time. The result shows the electrical tree growth process in unfilled $\mathrm{SiR}$ has a same trend with the SiR containing nano-alumina up to $2 \mathrm{vol} \%$ and Halloysite nanoclay up to 3 vol\%.

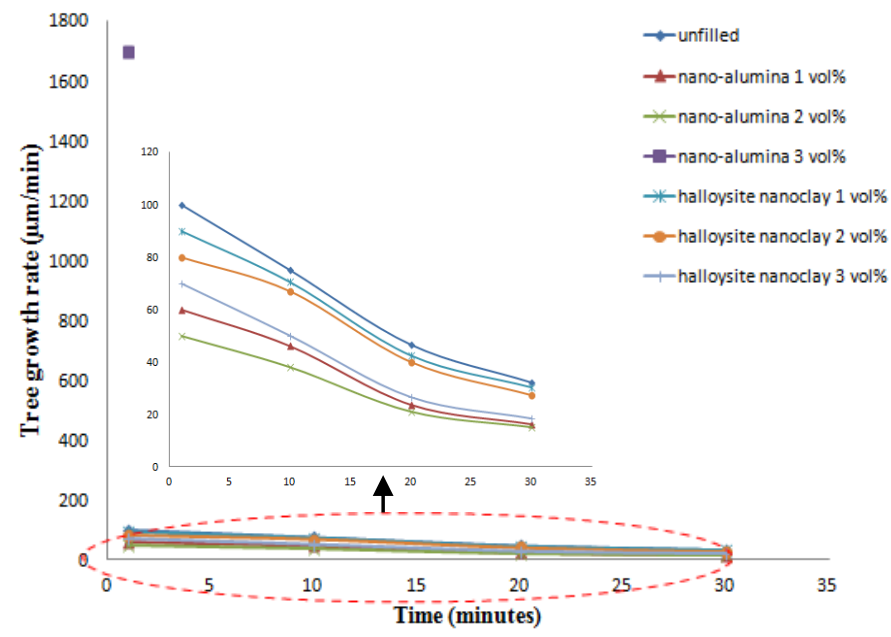

Fig 3 Electrical tree growth rate as a function of treeing time within 30 minutes at $8 \mathrm{kVrms}$

The electrical tree grew faster at the first 10 minutes and became slow at the last 20 minutes. The presence of 2 vol\% nano-alumina and 3 vol\% halloysite nanoclay in SiR have improved the electrical tree growth rate compared to unfilled SiR. These filler loading has prolonged the electrical tree growth process in the composite. However, the electrical tree growth faster at $3 \mathrm{vol} \%$ of nano-alumina compared to the others.

\section{Accumulate Damage}

The accumulate damage of the nanocomposite due to electrical tree growth path is analyzed by using ImageJ software. The covered area of insulation material for each photo taken was fixed at $1232 \mu \mathrm{m} \mathrm{x}$ $1354 \mu \mathrm{m}$ as shown in Fig 4. This automatic image analysis software is capable to calibrate the measurement scale, process and finally display the data measurement output effectively.

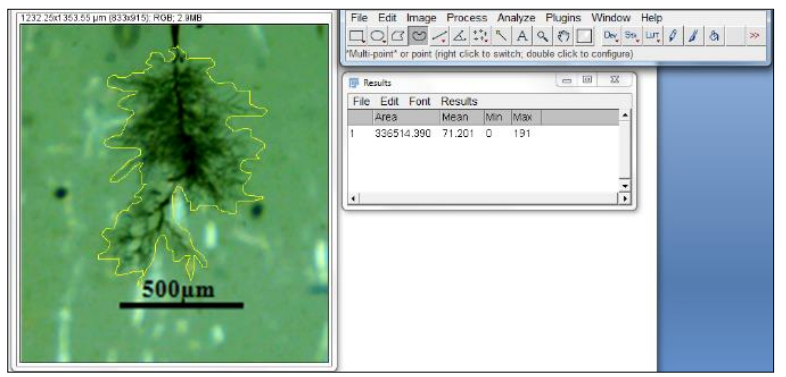

Fig 4 Accumulate damage measurement for unfilled SiR using Image J software

Fig 5 shows the typical type of electrical tree structure and accumulate damage in SiR nanocomposites at 30 minutes of electrical tree growth with $8 \mathrm{kVrms}$. It can be observed that, the carbonized area and accumulate damage in unfilled $\mathrm{SiR}$ is quite large as shown in Fig 5(a). Fig 5(b) and 5(c) show reduction of accumulate damage in SiR/Alumina nanocomposites with the presence of nano-alumina up to 2 vol\%. Meanwhile, the presence of halloysite nanoclay at 1, 2 and 3 vol\% of halloysite nanoclay in $\mathrm{SiR}$ as shown in Fig 5(d), 5(e) and 5(f) also indicate improvement of accumulate damage compared to unfilled SiR. 


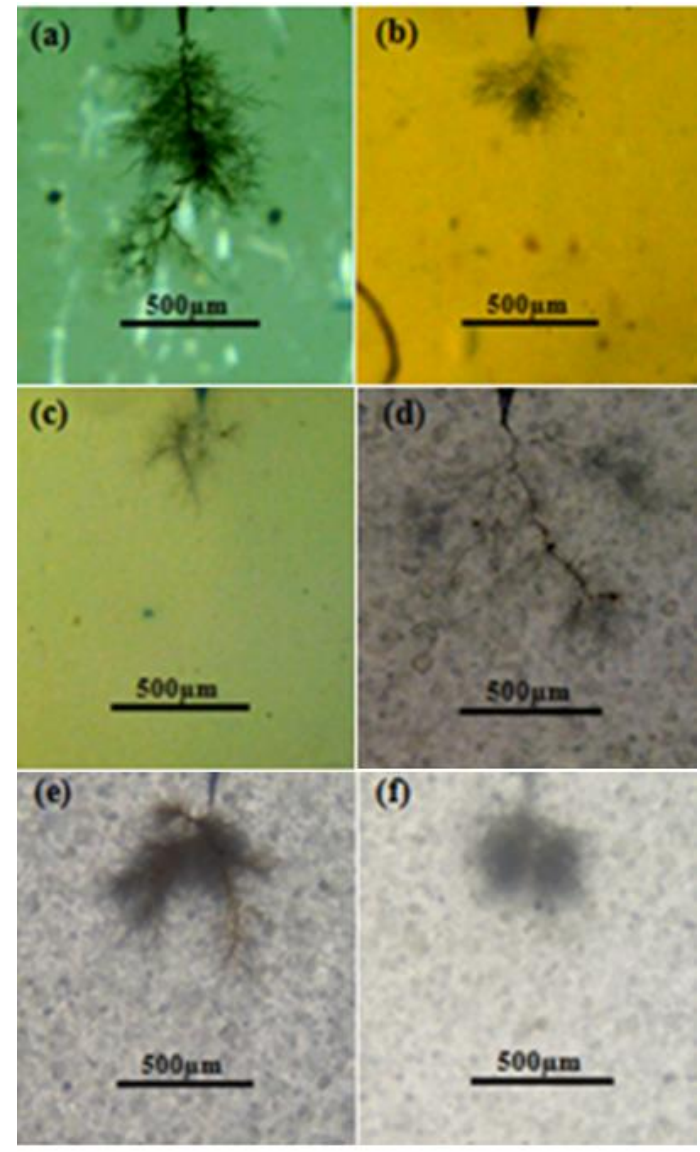

Fig 5 Typical type of electrical tree structure and accumulate damage in SiR nanocomposites with different concentration of filler captured at 30 minutes of electrical tree growth process (a)unfilled $\mathrm{SiR}$, (b) SiR with 1 vol\% nano-alumina, (c) $\mathrm{SiR}$ with 2 vol\% nano-alumina, (d) $\mathrm{SiR}$ with 1 vol\% halloysite nanoclay, (e) SiR with 2 vol\% halloysite nanoclay,(f)SiR with 3 vol\% halloysite nanoclay

Fig 6 depicts the electrical tree growth and accumulate damage in SiR nanocomposites at $3 \mathrm{vol} \%$ concentration of nano alumina.

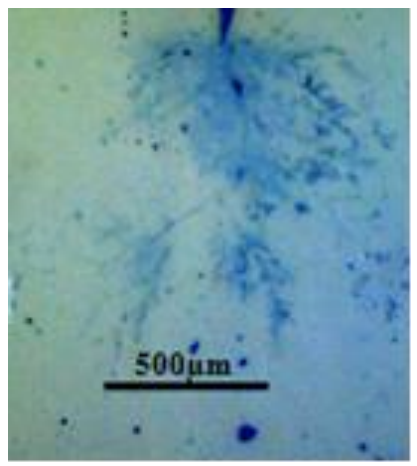

Fig 6 Electrical tree growth and accumulate damage in SiR with with 3 vol\% nano-alumina only at 1 minute of electrical tree growth process

It can be seen that the electrical tree growth path have deteriorated the worst area of insulation gap only at 1 minute of electrical tree growth process compared to the other $\mathrm{SiR}$ nanocomposites as discussed in Fig 5. The worst accumulate damage at 3 vol\% nano-alumina in $\mathrm{SiR}$ nanocomposites might be due to the agglomeration and overlapping of filler dispersion which contribute to the conductive path region area which finally led to the fastest electrical tree growth. The image captured

\section{SEM Image Analysis}

Fig 7 shows the image of Scanning electron microscopy (SEM) at 50K magnification for unfilled $\mathrm{SiR}$ and SiR filled with 3 vol\% nano-alumina and halloysite nanoclay. Fig 7(a) shows the SEM image of unfilled SiR while Fig 7(b) shows SEM image of 3 vol\% halloysite nanoclay.

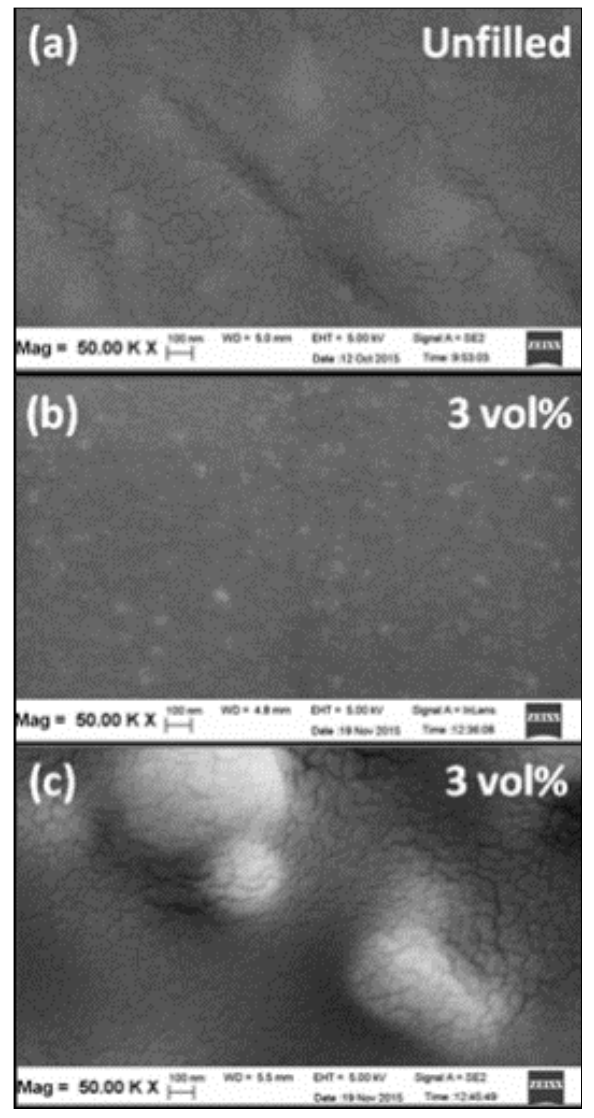

Fig 7 SEM image of unfilled $\mathrm{SiR}$ and $\mathrm{SiR}$ nanocomposites at different concentration of filler (a) unfilled $\mathrm{SiR}$, (b) $\mathrm{SiR}$ with 3 vol\% halloysite nanoclay, (c) SiR with 3 vol\% nanoalumina 
From the image, it is obviously depicts that the 3 vol\% of halloysite nanoclay is homogeneously dispersed in $\mathrm{SiR}$ that may offer better electrical tree growth rate and less of insulation damage than unfilled $\mathrm{SiR}$. This happens because of huge interfacial trap region area in $\mathrm{SiR}$ halloysite nanoclay compared to unfilled SiR [5].

However the presence of 3 vol\% nanoalumina in $\mathrm{SiR}$ nanocomposites yield to the agglomeration of nanofiller as shown in Fig 7(c) The agglomeration of nanofiller in $\mathrm{SiR}$ is believed to contribute to the overlapping of filler dispersion.This kind of filler dispersion offers the conductive path region which leads to the fastest electrical tree growth rate and the worst accumulate damage only at 1 minute of electrical tree growth process[18].

\section{CONCLUSION}

The effect of nano-alumina and halloysite nanoclay up to $3 \mathrm{vol} \%$ on electrical tree growth mechanism has been studied. It is observed that the presence of 2 vol\% nano-alumina and $3 \mathrm{vol} \%$ halloysite nanoclay in $\mathrm{SiR}$ nanocomposites show the slowest electrical tree growth rate and the less accumulate damage compared to unfilled SiR. It is believed that the improvement of electrical tree growth rate and accumulate damage is due to the reduction of inter particle distance in SiR nanocomposites which offers better electrical tree trap region area. However, it can be observed that there was obvious filler aggregation at $3 \mathrm{vol} \%$ nano-alumina which offers the conductive path region area in SiR nanocomposites. This kind of nanocomposites leads to the fastest electrical tree growth rate and the worst of accumulate damage only at 1 minute of electrical tree growth process.

\section{ACKNOWLEDGMENTS}

The authors would like to thank Universiti Sains Malaysia (USM) and Malaysia Ministry of Higher Education for financial support under the Fundamental Research Grant Scheme (FRGS: 6071265). The author would also like to thank the Department of Polytechnic especially Ministry of Education Malaysia for the financial and assistance offered for this project.

\section{REFERENCES}

[1] G. Chen and C. H. Tham, "Electrical treeing characteristics in XLPE power cable insulation in frequency range between 20 and $500 \mathrm{~Hz}$," IEEE Trans. Dielectr. Electr. Insul., vol. 16, no. 1, pp. 179-188, 2009.
[2] M. Nagao, K. Oda, K. Nishioka, Y. Muramoto, and N. Hozumi, "Effect of filler on treeing phenomenon in epoxy resin under AC voltage," Proc. 2001 Int. Symp. Electr. Insul. Mater. (ISEIM 2001). 2001 Asian Conf. Electr. Insul. Diagnosis (ACEID 2001). 33rd Symp. Electr. Ele, pp. 1112$1119,2001$.

[3] Y. Yamano, "Control of electrical tree at initiation stage in LDPE by mixed addition of $\mathrm{Al} 2 \mathrm{O} 3$ nanoparticle and azobenzoic compound," IEEE Trans. Dielectr. Electr. Insul., vol. 21, no. 1, pp. 209-216, 2014.

[4] M. Hafiz, M. Fairus, N. S. Mansor, M. Kamarol, M. Mariatti "Electrical tree characteristics with the addition of alumina in silicone rubber," Int. Conf. Proper. And. Dielectr. Materials, ICPADM pp. 47, 2015.

[5] T. Tanaka, G. C. Montanari, and R. Mulhaupt, "Polymer nanocomposites as dielectrics and electrical insulation-perspectives for processing technologies, material characterization and future applications," IEEE Trans. Dielectr. Electr. Insul., vol. 11 , no. 5 , pp. 763-784, 2004.

[6] M. G. Danikas and T. Tanaka, "Nanocomposites A review of electrical treeing and breakdown," IEEE Electr. Insul. Mag., vol. 25, pp. 19-25, 2009.

[7] a a Jamil, M. Kamarol, M. Mariatti, N. Bashir, M. H. Ahmad, Y. Z. Arief, and N. a. Muhamad, "Organo-montmorillonite as an electrical treeing retardant for polymeric insulating materials," Proc. 2012 IEEE Int. Conf. Cond. Monit. Diagnosis, C. 2012, no. September, pp. 237-240, 2012.

[8] S. Alapati and M. J. Thomas, "Electrical treeing in polyethylene: Effect of nano filler on tree inception and growth," 2010 Int. Conf. High Volt. Eng. Appl. ICHVE 2010, pp. 576-579, 2010.

[9] S. Alapati and M. J. Thomas, "Electrical treeing and the associated PD characteristics in LDPE nanocomposites," IEEE Trans. Dielectr. Electr. Insul., vol. 19, no. 2, pp. 697-704, 2012.

[10] B. Du, T. Han, and J. Su, "Tree characteristics in silicone rubber/SiO2 nanocomposites under low temperature," IEEE Trans. Dielectr. Electr. Insul., vol. 21, no. 2, pp. 503-510, 2014.

[11] Y. X. Zhou, R. Liu, F. Hou, W. Bin Xue, and X. Zhang, "Effect of silica particles on electrical treeing initiation in silicone rubber," Annu. Rep. Conf. Electr. Insul. Dielectr. Phenomena, CEIDP, pp. 609-611, 2012.

[12] M. Fairus , M. Hafiz, N. S. Mansor, M. Kamarol, M. Mariatti. Investigation on Dielectric Strength of Alumina Nanofiller with SiR/EPDM Composites 
for HV Insulator.Int. Conf. Proper. And. Dielectr. Materials, ICPADM pp. 4-7(2015)

[13] Mohanty, A. \& Srivastava, V. K. Dielectric breakdown performance of alumina / epoxy resin nanocomposites under high voltage application. Mater. Des. 47, 711-716 (2013)

[14]X. Huang, P. Jiang, and T. Tanaka, "A review of dielectric polymer composites with high thermal conductivity," IEEE Electr. Insul. Mag., vol. 27, 2011.

[15] N. Farzadnia, A. Abdullah, A. Ali, R. Demirboga, and M. Parvez, "Cement and Concrete Research Effect of halloysite nanoclay on mechanical properties, thermal behavior and microstructure of cement mortars," Cem. Concr. Res., vol. 48, pp. 97-104, 2013.

[16] H. C. Voon, R. Bhat, A. M. Easa, M. T. Liong, and a. a. Karim, "Effect of Addition of Halloysite Nanoclay and $\mathrm{SiO} 2$ Nanoparticles on Barrier and Mechanical Properties of Bovine Gelatin Films," Food Bioprocess Technol., vol. 5, pp. 1766-1774, 2012.

[17] S. Rooj, A. Das, and G. Heinrich, "Tube-like natural halloysite/fluoroelastomer nanocomposites with simultaneous enhanced mechanical, dynamic mechanical and thermal properties," Eur. Polym. J., vol. 47, no. 9, pp. 1746-1755, 2011.

[18] S. Singha, and M.J. Thomas, "Dielectric properties of epoxy nanocomposites", IEEE Trans. Dielectr. Electr. Insul., Vol. 15, No. 1, pp. 12-23, 2008. 